\title{
A Corpus-based Contrastive Study of Semantic Prosody of Basic Color Word in English and Chinese
}

\author{
Xingjia Chong \\ Gansu Cultural Translation and Interpreting Center \\ Lanzhou City University \\ Lanzhou, China
}

\author{
Mei Bai \\ School of Foreign Languages \\ Lanzhou City University \\ Lanzhou, China
}

\begin{abstract}
Semantic prosody is a kind of abnormal collocation in nature, and has been attached great importance to the definition and classification by researchers home and abroad. Based on data from BNC and LCMC, this paper tries to find the differences of basic color word in their lexical collocation and semantic prosody between English and Chinese. With the aid of Wordsmith Tools 5.0, the paper examines the semantic prosody of the English color word Black and its Chinese equivalent in the concordancing lines. The results indicate that there are similarities reflected by color words meaning system of objective world in English and Chinese.
\end{abstract}

Keywords-basic color word; lexical collocation; semantic prosody

\section{INTRODUCTION}

With the rapid development of computer technology since the 1980s, more achievements have been made in the field of corpus linguistics. A number of large-scale corpora were completed in this period. Corpus linguistics has experienced about 40 years' development history from the creation to the mature, through the integration of quantitative research and qualitative research, empirical research methods to led a historic change in the description of language, lexicography and translation studies. Halliday (1991) pointed out that "corpus linguistics is organically combined data collection and the theory together, which made the language undergo a qualitative change for us to understand." About 10 years later, Hunston (2002: 1) believed that, "it is not exaggerated to say that the corpus and the corpus research were carried out a revolution in the past few decades on language research and language application studies."

Semantic prosody is on more abstract level than collocations (Sinclair, 1991). It opened a new direction for modern corpus linguistics. Over the past 10 years, the linguists paid more and more attention to semantic prosody research which becomes a new and important object of the linguistic research. It is helpful for English learners to understand vocabulary and form good language expression from a new perspective through analysis and study of semantic prosody examples. At the same time it is also an important study object in corpus linguistics.

\section{LITERATURE REVIEW}

Semantic prosody is a main focus of corpus linguistics. It has aroused great interest ever since it was first observed by Sinclair (1991). It is a concept only recently discovered as the advent of computerized studies into language was needed before these semantic patterns could be noticed. In the study of corpus, people found some node words always attract a kind of collocations with same or similar semantic features which influence and infiltrate each other and they form a semantic atmosphere in context. As was found by Wei Naixing (2006: 50), some English words' collocated behavior showed a special trend, they used to attract a kind of lexical items with same or similar semantic features to form the collocation. Because of those collocations with same or similar semantic features appear with node words habitually, and usually, the node words are infected with relevant semantic features, and the whole span is filled with a special semantic atmosphere, that is what we called the semantic prosody of the node word.

In 1991, John Sinclair first noticed the phenomenon in his research that the term "set in" is habitually associated with unpleasant events. According to Sinclair (1991), "The initial choice of semantic prosody is the functional choice which links meaning to purpose; all subsequent choices within the lexical item relate back to the prosody." And he thinks that "semantic prosody is attitudinal and on the pragmatic side of the semantics/pragmatics continuum".

Later some other linguists offer their own definitions of semantic prosody based on their researches with different emphasis. Stubbs (1996) regards semantic prosody as "words occur in characteristic collocations showing the associations and connotations they have and therefore the assumptions which they embody". Partington (1998) defines semantic prosody as "the spreading of co notational coloring beyond single word boundaries". And according to Hoey (2000), semantic prosody is a phenomenon "when a word associates with a particular set of meanings" and "word occurs in the company of certain kinds of meaning rather than others".

In the area of semantic prosody, Louw (1993) studies the term "build up" and shows that when it is a transitive verb the semantic prosody is favorable, but as an intransitive verb its semantic prosody is unfavorable. Stubbs (1996) analyzes 40,000 examples of "cause" across 120 million words from 
the Cobuild corpus and highlights a negative tendency towards semantic prosody of collocates in the use of the verb cause. Channell (2000) investigates several examples, but he uses the term "pragmatic meaning" to refer to "semantic prosody" and "polarity" to the positive or negative sense in the concordance lines. One of the interesting results of his study is that the semantic prosody of the word "roams" is neutral, even sometimes positive, but the phrase "roam the street" involves a negative pragmatic meaning (semantic prosody). This means that semantic prosody is strongly collocational in that it operates beyond the meanings of individual words and it can spread across the sentence. Nelson (2000) creates a one million word Business English Corpus (BEC) for business lexis research. He investigates the key words in five categories the most frequent words in Business English corpus. His findings show that semantic prosody can be found in Business English. And he also indicates that different words have different strength in collocating with a particular set of words.

Ever since the concept of "semantic prosody" was introduced to China nearly a decade ago, it has aroused great academic interest among Chinese scholars. In 2000, Ji Yuhua and $\mathrm{Wu}$ Jianping first introduced the concept of semantic prosody to China. Then Wei Naixing (2002) explored three methods to study semantic prosody, namely data-based method, data-driven method and integration of the two methods. In 2005, Wang Zepeng and Zhang Yanchun once again traced back to the origin, theory and significance of semantic prosody. In 2008, Cheng Yunan discussed several definitions of semantic prosody and distinguished it from connotation and denotation.

\section{COMPARISON OF SEMANTIC PROSODY BETWEEN BLACK AND “黑”}

Language study can not only inspect the meaning of the word isolated, but put it in a linguistic units (words and collocations). To be the results of human's cognition, categorization and coding for color words in the vocabulary system, the words meaning system reflects the objective world of human life, and also reflects the different language community faced with a bit different world. Color semantic field is the typical semantic field to study the commonalities and differences of different language. In view of this, this article tries to compare the semantic prosody of basic color word Black in English and "黑" in Chinese through the use of modern concordancing tools.

\section{A. Lexical Collocations of Black and", 黑”}

With the aids of Wordsmith 5.0 and Excel Program, the paper uses data driven approach to study and analyze the semantic prosody of the English color word Black and its Chinese equivalent "黑” based on the corpora of BNC and LCMC.

The author collected all of the sample sentences at random from the concordancing lines in BNC in a proportion of one in fifty. "Table I" shows the frequency of the most commonly used collocates. In Fig. 1, Total means the frequency of the collocates exist in the corpus.
TABLE I. FREQUENCY OF COLLOCATES OF BLACK IN BNC

\begin{tabular}{|c|l|l|l|l|l|}
\hline No. & Word & Total & No. & Word & Total \\
\hline $\mathbf{1}$ & THE & 125 & $\mathbf{1 1}$ & ARE & 14 \\
\hline $\mathbf{2}$ & AND & 78 & $\mathbf{1 2}$ & IS & 12 \\
\hline $\mathbf{3}$ & A & 70 & $\mathbf{1 3}$ & AS & 11 \\
\hline $\mathbf{4}$ & OF & 60 & $\mathbf{1 4}$ & IT & 11 \\
\hline $\mathbf{5}$ & IN & 35 & $\mathbf{1 5}$ & ON & 11 \\
\hline $\mathbf{6}$ & TO & 28 & $\mathbf{1 6}$ & THAT & 11 \\
\hline $\mathbf{7}$ & WAS & 20 & $\mathbf{1 7}$ & AT & 10 \\
\hline $\mathbf{8}$ & WITH & 20 & $\mathbf{1 8}$ & THEY & 10 \\
\hline $\mathbf{9}$ & FOR & 17 & $\mathbf{1 9}$ & BY & 9 \\
\hline $\mathbf{1 0}$ & WHITE & 16 & $\mathbf{2 0}$ & HAD & 9 \\
\hline
\end{tabular}

From "Table I", we can't have an idea about which one is the typical collocation, for some of those themselves are high frequent words in English. It is necessary to make "Table II" by $\mathrm{T}$ score to search the collocation words of the node word-Black.

TABLE II. T-SCORES OF THE FIRST 20 COLLOCATES OF BLACK IN $\mathrm{BNC}$

\begin{tabular}{|c|l|l|c|l|l|}
\hline No. & Word & $\begin{array}{c}\text { T } \\
\text { Score }\end{array}$ & No. & Word & $\begin{array}{c}\text { T } \\
\text { Score }\end{array}$ \\
\hline $\boldsymbol{1}$ & THE & 11.175 & $\mathbf{1 1}$ & THE & 3.735 \\
\hline $\mathbf{2}$ & AND & 8.827 & $\mathbf{1 2}$ & AND & 3.452 \\
\hline $\mathbf{3}$ & A & 8.362 & $\mathbf{1 3}$ & A & 2.704 \\
\hline $\mathbf{4}$ & OF & 7.740 & $\mathbf{1 4}$ & OF & 2.753 \\
\hline $\mathbf{5}$ & IN & 5.909 & $\mathbf{1 5}$ & IN & 2.779 \\
\hline $\boldsymbol{6}$ & TO & 5.283 & $\mathbf{1 6}$ & TO & 2.727 \\
\hline $\boldsymbol{7}$ & WAS & 4.463 & $\mathbf{1 7}$ & WAS & 2.759 \\
\hline $\boldsymbol{8}$ & WITH & 4.465 & $\mathbf{1 8}$ & WITH & 2.813 \\
\hline $\boldsymbol{9}$ & FOR & 4.113 & $\mathbf{1 9}$ & FOR & 2.583 \\
\hline $\mathbf{1 0}$ & WHITE & 4.000 & $\mathbf{2 0}$ & WHITE & 2.66 \\
\hline
\end{tabular}

"Table II" shows that the T score of those twenty words are all bigger than 2.0. (T score reflects the extent to which the presence of typical collocation in the co-occurrence of words. According to the convention of co-build, we always regard that the collocation word which has the $\mathrm{T}$ score bigger than 2.0 is typical collocation). From Fig.2 and the context, we see that the majority of the collocations express the negative meaning. To further observe and analyze the extended context of those 20 index lines provided by BNC, the author found that there are 7 examples with neutral semantic prosody, 11 examples with negative semantic prosody and 2 examples with positive semantic prosody.

The author collected all of the sample sentences at random from the concordancing lines from LCMC.

TABLE III. FREQUENCY OF COLLOCATES OF “黑” IN LCMC

\begin{tabular}{|c|l|l|l|l|l|}
\hline Number & Word & Total & Number & Word & Total \\
\hline $\mathbf{1}$ & 马 & 8540 & $\mathbf{1 1}$ & 河 & 4351 \\
\hline $\mathbf{2}$ & 色 & 15201 & $\mathbf{1 2}$ & 客 & 3111 \\
\hline $\mathbf{3}$ & 白 & 13723 & $\mathbf{1 3}$ & 市 & 7423 \\
\hline $\mathbf{4}$ & 山 & 7599 & $\mathbf{1 4}$ & 夜 & 6775 \\
\hline $\mathbf{5}$ & 棋 & 1047 & $\mathbf{1 5}$ & 海 & 7493 \\
\hline $\mathbf{6}$ & 人 & 39973 & $\mathbf{1 6}$ & 帮 & 2257 \\
\hline $\mathbf{7}$ & 烟 & 2457 & $\mathbf{1 7}$ & 金 & 6034 \\
\hline $\boldsymbol{8}$ & 暗 & 11080 & $\mathbf{1 8}$ & 幕 & 1512 \\
\hline $\boldsymbol{9}$ & 洞 & 2123 & $\mathbf{1 9}$ & 哨 & 369 \\
\hline $\mathbf{1 0}$ & 豆 & 824 & $\mathbf{2 0}$ & 手 & 12347 \\
\hline
\end{tabular}


From "Table III", we can't have an idea about which one is the typical collocation, for some of those themselves are high frequent words in Chinese. It is necessary to make Fig. 4 by $\mathrm{T}$ score to search the collocation words of the node word “黑”. There are 20 collocates of “黑” resented in "Table IV" with T-scores:

TABLE IV. T-SCORES OF THE FIRST 20 COLLOCATES OF “黑” IN LCMC

\begin{tabular}{|c|l|l|l|l|l|}
\hline No. & Word & T Score & No. & Word & T Score \\
\hline $\mathbf{1}$ & 马 & 91.811 & $\mathbf{1 1}$ & 河 & 65.545 \\
\hline $\mathbf{2}$ & 色 & 122.893 & $\mathbf{1 2}$ & 客 & 55.259 \\
\hline $\mathbf{3}$ & 白 & 116.772 & $\mathbf{1 3}$ & 市 & 84.606 \\
\hline $\mathbf{4}$ & 山 & 86.513 & $\mathbf{1 4}$ & 夜 & 82.085 \\
\hline $\mathbf{5}$ & 棋 & 32.250 & $\mathbf{1 5}$ & 海 & 85.675 \\
\hline $\mathbf{6}$ & 人 & 197.622 & $\mathbf{1 6}$ & 帮 & 47.123 \\
\hline $\mathbf{7}$ & 烟 & 49.346 & $\mathbf{1 7}$ & 金 & 76.705 \\
\hline $\mathbf{8}$ & 暗 & 105.164 & $\mathbf{1 8}$ & 幕 & 38.597 \\
\hline $\mathbf{9}$ & 洞 & 45.944 & $\mathbf{1 9}$ & 哨 & 19.128 \\
\hline $\mathbf{1 0}$ & 豆 & 28.600 & $\mathbf{2 0}$ & 手 & 110.359 \\
\hline
\end{tabular}

"Table IV" shows the T score of those 20 words are all bigger than 2.0. From the table and context, we see that the majority of the collocations express the negative meaning. To further observe and analyze the samples of those 20 words, the author found that there are 6 examples with neutral semantic prosody, 11 examples with negative semantic prosody and 3 examples with positive semantic prosody.

\section{B. The Comparison of Semantic Prosody between Black and “黑”}

Stubbs (1996) once has divided semantic prosody into three types: positive semantic prosody, neutral semantic prosody and negative semantic prosody. In the positive semantic prosody, the node word always attracts the words that almost all have positive semantic features, which forms a positive atmosphere. In the neutral semantic prosody, the node word not only attracts the words with negative meaning, but also attracts the words with positive or neutral meaning to form a complex semantic atmosphere. In negative semantic prosody, the node word attracts the words that almost all have negative semantic features, which make the whole context is enveloped in a negative semantic atmosphere.

The author uses the statistics from "Table II" and "Table IV" to make "Table V" and the author will observe and analyze the samples of different semantic prosody about Black and “黑”.

TABLE V. COMParison of Semantic Prosody of Black AND “黑”

\begin{tabular}{|c|l|l|l|}
\hline Word & Positive & Neutral & Negative \\
\hline Black & $10 \%$ & $35 \%$ & $55 \%$ \\
\hline “黑” & $15 \%$ & $30 \%$ & $55 \%$ \\
\hline
\end{tabular}

From "Table V", we can see that in the positive semantic prosody, English word Black takes up 10\%, while Chinese word “黑” covers 15\%. In neutral semantic prosody, Black covers 35\%, but “黑” takes up 30\%. Also in the negative semantic prosody, Black takes up 55\%, so does the Chinese word “黑”. Thus we can see that both Black and "黑” are mostly used to express negative semantic prosody. Then they express more neutral semantic prosody than positive semantic prosody. Through the comparison, we can also see that the negative semantic prosody of Black and "黑" is equal, and the neutral semantic prosody of Black is higher than “黑”. At the same time, the positive semantic prosody of Black is lower than "黑”. The results indicate that there are similarities reflected by color words meaning system of objective world in English and Chinese, but due to physical, psychological or physiological ethnic differences, and the different custom and language expressing habits, there are differences in practical application between two languages in the same color words.

\section{CONCLUSION}

The corpus provides a real, rich, meaningful linguistic environment for language learners, thereby the learners can place themselves into the real language learning environment clearly; in vocabulary learning, we should lead into the concept of semantic prosody, because the correct use of the semantic prosody is directly related to the accuracy and genuineness.

As for this paper, the authors simply study and analyze the comparison and translation of the semantic prosody between Black and “黑”. The authors find that both Black and “黑” are mostly used to express negative semantic prosody. Then they express more neutral semantic prosody than positive semantic prosody. Through the comparison, we can also see that the negative semantic prosody of Black and "黑” is equal, and the neutral semantic prosody of Black is higher than "黑”. At the same time, the positive semantic prosody of Black is lower than "黑”.

The results indicate that there are similarities reflected by color words meaning system of objective world in English and Chinese, but due to physical, psychological or physiological ethnic differences, and the different custom and language expressing habits, there are differences in practical application between two languages in the same color words.

\section{REFERENCES}

[1] Channel, J. Corpus-Based Analysis of Evaluative Lexis [A]. In Hunston S. and Thompson G. (Ed.), Evaluation in Authorial and the construction of discourse [C]. New York: Oxford University Press, 2000.

[2] Hunston. S and Thompson, G. Evaluation in Authorial and the construction of discourse [M].New York: Oxford University Press, 2000.

[3] Louw, B. Irony in the txt or insincerity in the writer? The diagnostic potential of semantic prosodies[A]. In Baker M, Francis G. and Tognini-Bonelli E.(ed.) Text and Technology: In Honour of John Sinclair[C].Amsterdam: John Benjamins, 1993.

[4] Nelson, M. A Corpus-Based Study of Business English and Business English Teaching Materials. 2000.

[5] Partington, A. Patterns and Meanings-Using Corpora for English Research and Teaching [M]. Amsterdam/Philadelphia: John Benjamins, 1998 
[6] Sinclair, J. M. Corpus, concordance, collocation [M]. Oxford: Oxford University Press, 1991.

[7] Stubbs, M. Text and Corpus Analysis [M]. Oxford: Blackwell, 1996.

[8] Xiao, R. and MeEnery A. Collocation, semantic prosody, and near synonymy: A cross-linguistic perspective [J]. Applies Linguistics, 2006, 27(1): 103-129.

[9] Yutong, Cheng. Reexaming Semantic Prosody and Attitudinal Meaning[D], Shanghai Jiaotong University, 2007.

[10] .Yuhua, Ji and Jianping, Wu. Study of Semantic Prosody: Object, Methods and Applications[J]. Journal of Xiamen University,2000.

[11] Zepeng, Wang and Yanchun, Zhang. The Theory of Semantic Prosody J]. Journal of Tongji University, 2005(4).

[12] Naixing, Wei. Methods of Semantic Prosody Studies [J]. Foreign Language Teaching and Research,2002(4).

[13] Naixing, Wei. A Corpus -based Contrastive Study of Semantic Prosodies in Leaner English.Foreign Language Research, 2006(5). 